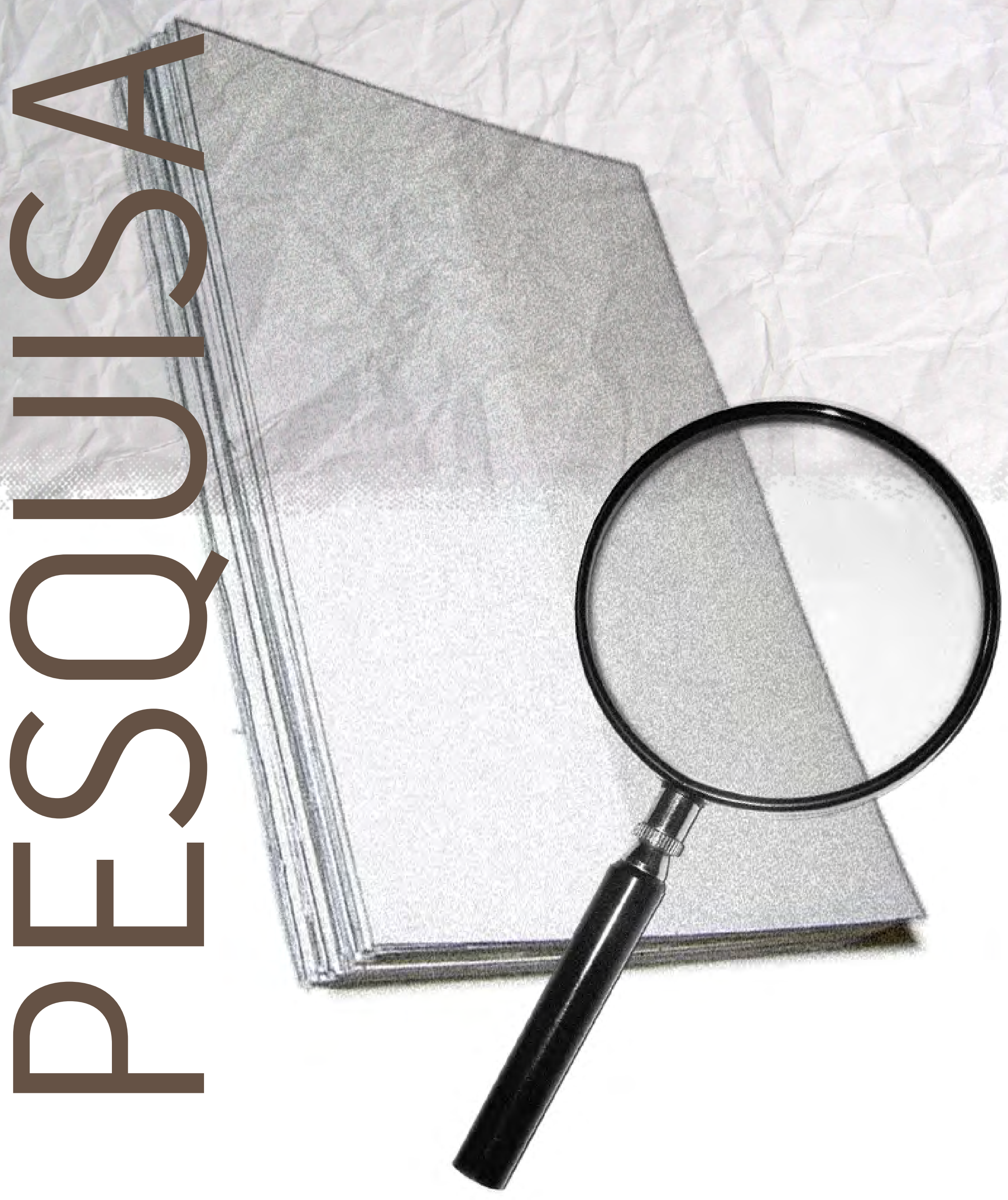




\section{Fãs organizacionais e o discurso mnêmico nas mídias sociais: observações a partir do estudo do Canal Viva}

\section{Organizational fans and the mnemonic discourse in the social media: notes based on the study of the Viva Channel}

\section{Fans organizacionales y el discurso mnémico en los medios sociales: observaciones a partir del estudio del Canal Viva}

\section{Adriana da Rosa Amaral}

- Doutora e mestre em Comunicação Social pela Pontifícia Universidade Católica do Rio Grande do Sul (PUC-RS)

- Graduada em Jornalismo pela PUC-RS

- Docente do Programa de Pós-Graduação em Ciências da Comunicação da Universidade do Vale do Rio dos Sinos (Unisinos)

- Coordenadora da Especialização em Cultura Digital e Redes Sociais da Unisinos

- Coordenadora dos grupos de pesquisa "Creative industries, cities and popular music scenes: the social media mapping of urban music scenes" e "Cartografias do urbano na cultura musical e audiovisual: som, imagem, lugares e territorialidades em perspectiva comparad", da Unisinos

- $\quad$ Autora do livro Visões perigosas: uma arque-genealogia do cyberpunk. Comunicação e cibercultura e coautora do livro Métodos de pesquisa para internet

- E-mail: adriana.amaral08@gmail.com

\section{Augusto Rodrigues Parada}

- Doutor em Ciências da Comunicação pela Universidade do Vale do Rio dos Sinos (Unisinos)

- Mestre em Comunicação Social e graduado em Jornalismo pela Pontifícia Universidade Católica do Rio Grande do Sul (PUC-RS)

- Docente dos cursos de Publicidade e Propaganda e Relações Públicas das Faculdades Integradas de Taquara (Faccat)

- Coordenador dos cursos de graduação em Relações Públicas, Publicidade e Propaganda e Design da Faccat

- Coordenador da Especialização em Comunicação e Marketing Empresarial da Faccat

- Coautor do livro A comunicação e a fé em sociedades em midiatização

- E-mail:aparada@faccat.br 


\section{Resumo}

A perspectiva abordada na discussão a seguir parte do pressuposto de existência de um fã organizacional que, em virtude de um comportamento próprio, se estabelece como um público de interesse das organizações. A partir de tal categorização, e usando como foco de estudo o Canal Viva, do Grupo Globo, consegue-se elencar quais seriam os padrões de comportamento desse novo público e, mais, de que forma as trocas simbólicas se concretizam como fatores de identificação e relacionamento entre os fãs e as organizações em espaços digitais. Assim, tais panoramas apontam para um olhar sobre possíveis articulações comunicacionais por parte das organizações para a manutenção desse relacionamento.

\section{PALVRAS-CHAVE: FÃS・RELACIONAMENTO・MEMÓRIA •FÃS ORGANIZACIONAIS・CANAL VIVA}

\section{Abstract}

The perspective addressed in the following discussion presumes the existence of an organizational fan that, due to a unique behavior establishes him/herself as a public of interest for the organizations. Starting from this classification and using as a focus of study the Viva Channel, of the Globo Group, one can list what would be the standard of behavior of this new public and, further, in which way the symbolic exchanges materialize as factors of identification and relationship between the fans and the organizations in digital spaces. Thus, these scenarios point to possible communicational articulations on the part of the organizations for the maintenance of such relationship.

KEYWORDS: FANS • RELATIONSHIP・MEMORY • ORGANIZATIONAL FANS・VIVA CHANNEL.

\section{Resumen}

La perspectiva abordada en la discusión a continuación parte del presupuesto de la existencia de un fan organizacional que, en virtud de un comportamiento proprio, se establece como un público de interés de las organizaciones. A partir de tal categorización, y usando como foco de estudio el Canal Viva, del Grupo Globo, se consigue enumerar cuáles serían los padrones de comportamiento de ese nuevo público y, más, de qué forma las trocas simbólicas se concretizan como factores de identificación y relacionamiento entre los fans y las organizaciones en espacios digitales. Así, tales panoramas apuntan para una mirada sobre posibles articulaciones comunicacionales por parte de las organizaciones para la manutención de ese relacionamiento. 
M

uitas organizações são relutantes com as redes sociais digitais, por medo do impacto que elas podem causar (Ciribeli; Paiva, 2011). A boa inserção nas redes sociais demanda a criação de estratégias e ações de monitoramento.

Uma vez que a organização está presente no ambiente digital, ela precisa de planos de presença, engajamento e relacionamento com os públicos. Esse processo inclui "desde a proposta comunicacional estratégica da organização e 0 trânsito das mensagens por suportes midiáticos, até a interpretação subjetiva dos diferentes públicos" (Terra, 2011, p. 13). Dentro dessa trajetória é que se consolida, então, a nossa discussão sobre o fã organizacional. Num primeiro momento discutiremos o papel dos fãs na cultura midiática, o fã de marcas, e caracterizaremos o fã organizacional, cuja proposta de categoria é decorrente da análise empírica realizada sobre os fãs do Canal Viva nas plataformas digitais (Parada, 2015)'. A emergência da categoria fã organizacional em sua articulação com os elementos identitários de nostalgia e memória pode contribuir para as relações entre as organizações e esse tipo específico de público.

\section{UMA BREVE DISCUSSÃO SOBRE O PAPEL DOS FÃS NA CULTURA MIDIÁTICA}

A definição de fã pode ter vários entendimentos e interpretações². Contudo, transpostas nos meios digitais, as ações dos fãs se expandiram. A partir dos estudos sobre a cultura dos fãs, é possível observar a mudança cultural ocorrida nas últimas décadas, em que o consumidor migra das margens para o centro das atenções da indústria midiática. A participação deles passou a ser vista como uma parte normal do processo da mídia e, mais, a percepção do seu encontro em ambientes próprios traz à tona uma dinâmica em que eles têm condições midiáticas de se manterem sem o direcionamento da mídia, uma vez que as comunidades de fãs constroem sua própria cultura de convergência e identidade através da interação social. Nos fandoms - grupos ou comunidades de fãs - esse compartilhamento de interesses e sentimentos entre os membros, ao construírem uma identidade do todo e ao gerarem identificação dos participantes, acabam por produzir conteúdo, comportamentos, produtos, entre outros.

\section{0 fã de marcas}

A marca pode oferecer pontos de contato através da web para estimular comunicações mais amplas e até mesmo apaixonadas. Mesmo não conseguindo um engajamento através de conversas, ela pode criar experiências significativas e se tornar importante na vida das pessoas (Aaker; Joachimsthaler, 2007). A presença on-line da marca inclui também formas de comunicação que não são controladas pela organização - salas de bate-papo, grupos de discussões, sites de redes sociais etc.

A constituição de uma economia afetiva incentiva as empresas a transformarem as marcas em lovemarks (Roberts, 2005) cuja perspectiva é a de um relacionamento expressivo e um contato constante com o público que relacione a própria marca com atributos muito íntimos ao público. É a atenção às histórias pessoais, aos desejos de consumo, às experiências trocadas e à intimidade que emergem como processuais na relação do consumidor com as marcas que ele ama. Os públicos divulgam as suas impressões sobre a marca, seja compartilhando informações ligadas a ela, ou demonstrando o seu afeto de variadas maneiras. Tais constatações mercadológicas do tema encontram amparo nos pressupostos de Michel Maffesoli. Ao apontar a regressão da razão, o autor sinaliza outros pressupostos do constitutivo social, baseados no emocional, experiencial e simbólico, que reverberam não apenas nas práticas comunicativas, na sociabilidade, nos constitutivos culturais, mas também em uma economia do futuro, uma economia emocional (Natal, 2009).

1 Nesse artigo ampliamos algumas discussões retiradas da tese de doutoramento de Augusto Parada (2015) no qual o objeto de análise foram os fãs organizacionais do Canal Viva a partir das postagens a respeito da telenovela Dancin' Days. Nesse sentido, o Canal Viva foi pensando como uma organização e a telenovela como seu produto. 2 Além de Henry Jenkins (2009), uma série de autores problematizou o conceito como Cornel Sandvoss (2005) e Francesca Coppa (2006), entre outros. 
Assim, as expressões de fidelidade devem ser vistas como um investimento na marca, (Jenkins, 2009), não somente com a sua exposição, mas também como um grau de intimidade do consumidor, que se percebem parte da construção da mesma (Roberts, 2005). 0 potencial colaborativo e o comprometimento dos fãs consumidores na internet, se dão em torno de um interesse comum, um produto ou uma pessoa, podendo levar uma marca ao status de lovemark. A internet é um campo fértil para o derramamento do poder que uma marca de amor traz (Natal, 2009).

\section{O fã organizacional: uma proposta de categorização de público}

Aproximar a cultura dos fãs de algumas estratégias de comunicação organizacional é o que se intenciona, no momento em que assumimos que o fã organizacional tem um comportamento próprio que se concentra em ambientes digitais ofertados pelas organizações. Articular esses dois aspectos sugere uma análise que contemple tanto elementos supostamente estratégicos, quanto construções comportamentais dos públicos.

Apesar de o fã organizacional pode ser qualquer pessoa, uma vez que se estabeleça o relacionamento com uma organização, entendemos que é um público heterogêneo, desmembrado geograficamente e que é interpelado por variáveis socioeconômicas, culturais e políticas que ocorrem na sociedade e nas organizações. Os relacionamentos se estabelecem a partir do compartilhamento de ideias e visões. Ele não pode ser classificado dentro de uma ou de outra definição tradicional de públicos de uma organização. Ele constitui um público de interesse, diverso e multifacetado, que opina, decide, constrói, influencia e é influenciado pela própria organização, principalmente em seu comportamento. Ele se estabelece à medida que dá voz as suas concepções pessoais e se relaciona com atores sociais que se aproximam ou se afastam de suas posições.

A constituição de uma relação de interesse é fomentada pela troca de informações ou mensagens, pela expressão comportamental que a organização entende como um acordo de manutenção desse relacionamento. Existe uma "nãolinearidade controlada" da comunicação que a organização estabelece com o fã. Os componentes do processo têm liberdade comunicacional, contudo são estimulados a expressarem essa liberdade em ambientes controlados pela organização. Nesses espaços controlados é que se estabelecem, também, as trocas simbólicas, por vezes dotadas de intervenções discursivas pessoais e coletivas, e, por sua vez, é onde as organizações têm a possibilidade de se aproximar dos públicos. Ao estabelecer condições para que o público tenha experiências significativas, eles se tornam ambientes de relacionamento ricos de opiniões, desejos, histórias - importantes para a vida das pessoas e para a aproximação das organizações com elas. Um dos comprometimentos das organizações com seus fãs deve ser o da liberdade de significados e referências, concepções e pontos de vistas presentes nas manifestações dos públicos nesses ambientes.

Algumas características comportamentais se evidenciam nessa primeira proposta. A primeira delas é a de ser um público ativo em ambientes digitais em rede. Mais do que isso, encontram-se nessas plataformas para produzir e compartilhar conteúdos, utilizando interligações para processar a construção de conhecimentos. É também nesses ambientes que os públicos conseguem encontrar espaço para acompanhar a circulação de informações de interesse por outras mídias. Todavia, mesmo acompanhando os assuntos de seu interesse em outras mídias, suas impressões e experiências voltam para ser comentadas nesses espaços de partida Assim, além de estar em ambientes digitais em rede, os fãs organizacionais concentram-se em espaços de direcionamento para outras mídias, fomentam a circulação de conteúdos de seus interesses por outros meios e voltam para os espaços de direcionamento para fazer suas considerações e impressões. 
principalmente entre os pares que estão dispostos a discutir um assunto, para tecer opiniões não favoráveis ao que vem sendo ofertado pela organização. Esse estímulo à expressão, mesmo que negativa, pode ser promovida pela organização, de forma explícita (quando uma empresa/marca convida o consumidor a se expressar por meio de mensagens diretas) ou de forma subjetiva (pela consciência da organização em garantir essa liberdade de expressão). Essa tonalidade liberal das expressões conduz para que os públicos, naturalmente, se identifiquem pelos gostos, pelas preferências, pelas deferências e assim, em conjunto, criem uma lógica de definição das preferências do grupo.

Um dos elementos-chave para o processo de constituição do fã organizacional passa por uma necessidade deles de agrupamento e socialização, aquilo que chamamos de fandoms organizacionais. Estes seriam os espaços interligados de expressões do público, contudo ofertados pela organização, como uma peça de sua postura comunicacional. As organizações estabelecem esses ambientes controlados de compartilhamento de conhecimento para que o público gere conteúdo, que por sua vez também pode ser utilizado pela própria organização. Ao se disponibilizarem plataformas on-linede conversação, geração de conteúdo e compartilhamento (em sua maioria sites de "redes sociais"), criam-se laços de identificação dos fãs com as organizações, principalmente por se tratar de espaços repletos de discursos não institucionais e que, por serem dotados de pessoalidades, tornam mais íntima essa relação.

Conforme visto até aqui, estabelecemos uma condição de existência do fã organizacional: existe um movimento próprio dos grupos de fãs que se expressam em plataformas on-line disponibilizadas pelas organizações. Mais do que isso, os comportamentos típicos dos fãs são estimulados pelas organizações, que entram no processo de conversação, construção colaborativa e compartilhamento e geração de conteúdo, por meio de um posicionamento comunicativo organizacional de dar voz ao público. 0 insight para essa pesquisa foi de que maneira o Canal Viva usaria o elemento da memória na condução do relacionamento com seus fãs organizacionais.

\section{OS FÃS ORGANIZACIONAIS DO CANAL VIVA: PRIMEIRAS OBSERVAÇÕES}

Ao conduzirmos a pesquisa para o uso da memória como promotora de relacionamentos entre organização (Canal Viva) e seus fãs, emergem dúvidas sobre que expressão dessa memória seria mais comum de se encontrar nos fandoms organizacionais: a memória da organização (sua reputação, suas histórias, as lembranças de seus produtos e serviços); a memória individual (do fã enquanto ator social e estimulado a compartilhar seu conhecimento comum); ou a memória coletiva (e as expressões simbólicas do imaginário que identificam um grupo) $)^{3}$.

Aline Maia (2007) ressalta que os meios de comunicação e, sobretudo, produtos midiáticos como as telenovelas são relevantes e decisivos na construção das memórias, das identidades, por ser esse um sistema processual com base em diálogos abertos e dinâmicos. A comunicação, com suas premissas interativas, consolida o processo de constituição de identidades a partir de discursos imagéticos e mnêmicos. Esses discursos do imaginário são transformados constantemente pelas mídias. A realidade cotidiana é reinventada em um programa de televisão, que recria elementos do imaginário social, influenciando dinâmicas sociais, que, por sua vez, voltam a ser representadas pelos programas de televisão em um processo de retroalimentação. Nesse contexto, elementos como a memória e a nostalgia acionam emoções e subjetividades dos fãs.

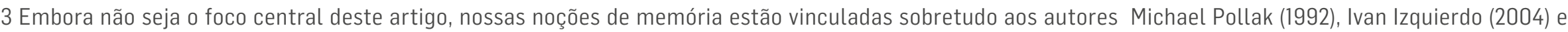
Paulo Nassar (2008). 


\section{Nostalgia e sua mercantilização}

O sentimento de perda, de ausência, de fuga é comum ao homem que, frustrado com algum elemento de sua realidade, percorre um caminho psíquico para situações tidas como mais agradáveis e alocadas em seu passado. Beneduzzi (2005), ao resgatar os traços da imigração italiana no Rio Grande do Sul, discorre amplamente sobre o termo nostalgia ao longo da história.

Segundo 0 autor, o termo era empregado clinicamente nos exércitos, como um tipo de doença psíquica grave, com alta capacidade de mortalidade, caracterizada pela dor atribuída ao não-retorno dos soldados à pátria-mãe. 0 tratamento que se dava na época era o de fazer esses soldados retornarem aos seus países, a fim de minimizar os sintomas da nostalgia, ou apenas prometer a eles um retorno - 0 que já ajudava nessa melhora. 0 principal sintoma era a tristeza, sentimento marcante da nostalgia até seu entendimento mais recente. Uma das aliadas desse condicionamento psíquico seriam as causas físicas, em uma clara associação aos lugares geográficos. As mudanças geográficas, por exemplo, seriam causadoras da nostalgia, uma vez que, ao se deslocarem de um espaço para outro, condições climáticas adversas provocavam um esforço maior para respirar e garantir as funções anatômicas, que ficavam mais lentas em virtude dessa mudança. Essa prostração, esse cansaço causado por tal deslocamento, também caracterizariam a nostalgia (Beneduzzi, 2011).

0 autor também fala que Kant, mais tarde, vai adicionar ao entendimento da nostalgia o caráter temporário, dando protagonismo ao passado, e percebendo como constitutivo do sentimento nostálgico a impossibilidade do retorno, a irreversibilidade do tempo e que o espaço da recordação é o ambiente do nostálgico. No século XIX, com as crescentes transformações sociais, grandes capacidades produtivas, tal sentimento de nostalgia ganha força. Perde-se a referência daquilo que antes dava conforto e identidade ao homem.

Por fim, ele retrata que a atualidade da nostalgia está marcada pelo desejo de retorno. Diferentemente de uma doença psíquica, ela é uma "reação a determinadas situações e acontecimentos da vida do indivíduo" (Beneduzzi, 2011, p. 222). Se antes, a nostalgia era tida como uma constituição de lugares não revisitados, agora ela passa a fazer parte do imaginário, carregando experiências, imagens, sentimentos, simbolismos presentes no passado (Beneduzzi, 2011).

É nessa última esfera que vamos concentrar a ideia de nostalgia e, mais, é a partir dela que vamos conduzir o comportamento do consumidor e dos fãs, a fim de estabelecê-la como um elemento presente nas práticas de consumo e nas relações entre fãs e as produções televisivas. 0 exercício do consumo faz parte da condição humana e, em consequência disso, da vida dos indivíduos em sociedade. Ultrapassando as ideias de satisfação de necessidades, e de desejos de compra aliados ao status, são as condições mais modernas de entendimento do consumo que nos interessam. Dois pontos passaram a ser cruciais para a percepção da sociedade de consumo: a emoção e o individualismo.

O primeiro, relacionado aos sentimentos dos indivíduos, ultrapassa o desejo e o anseio, e cria um conforto emocional ao se consumir determinado produto, ou usufruir de algum serviço. 0 segundo, intrinsecamente ligado ao primeiro, caracteriza-se pelo consumo próprio, para a satisfação individual, não-coletiva. "O consumismo moderno tem mais a ver com sentimentos e emoções, manifestadas através do desejo, do que com razão e calculismo, na medida em que é claramente individualista, em vez de público, em sua natureza" (Barbosa; Campbell, 2006, p. 49).

É nesse ponto sobre os sentimentos, as emoções, que o comportamento de consumo, em nosso recorte, realiza seu encontro com a nostalgia. Em 1980, Holbrook (1993) começou a desenvolver uma escala de mensuração das tendências nostálgicas dos indivíduos, identificando o gosto pelo passado e pelo presente e fazendo suas devidas relações para avaliar esse grau 
de nostalgia. Essa escala foi publicada, em 1993, no Journal of Consumer Research. 0 próprio autor percebeu que, além de padrões estéticos e artísticos, existia uma tendência de consumo vinculada à nostalgia, identificada como a preferência por objetos que eram mais comuns quando se era mais jovem (Holbrook; Schindler, 2003).

Visivelmente a noção de temporalidade resgata o ideal de nostalgia; contudo, esse comportamento de consumo se estabelece a partir da possibilidade de adquirir esses objetos, recriando aquelas sensações do passado. Esse retorno de sentidos recarrega o termo nostalgia de metáforas e imagens, tornando-a uma articuladora entre o passado e o presente.

Entre os assuntos mais presentes no estudo de Holbrook e Schindler (2003) sobre as associações com a nostalgia, estão as experiências sensoriais, os ritos de passagem, o lar, a amizade e pessoas amadas, os presentes de amor, a fuga, a segurança, a arte e 0 entretenimento, o desempenho e a competência e a criatividade. Os autores relacionam que cada objeto nostálgico remete a uma dessas categorizações.

Ampliando um pouco mais essa visão que tem uma forte inclinação aos objetos do passado, invocamos a nostalgia como uma proposta de prazer com o passado, uma vez que alivia a frustração com o presente (Goulding, 2001). Vale, também, retomar mais um ponto da discussão de Holbrook (1993), quando o autor salienta que a nostalgia normalmente é um sentimento comum aos indivíduos; porém, essa negação do presente e exaltação do passado não precisa, necessariamente, estar vinculada a um evento vivido.

\section{Fãs, memória e comunicação organizacional}

A partir da coleta de dados da pesquisa e realizadas as primeiras interpretações acerca do que foi visto nas expressões dos públicos nos ambientes digitais institucionalizados pelo Canal Viva ${ }^{4}$, três enfoques analíticos são propostos a fim de se concretizarem os elementos constitutivo dos fãs organizacionais: 1) Como o fã do Canal Viva se comporta nesses espaços; 2) qual o papel da memória nesse relacionamento entre público e organização; 3) qual a postura comunicacional adotada e qual poderia ser mais efetiva.

Entendemos que, quando se afirma que qualquer pessoa pode ser um fã organizacional, a assiduidade nesses espaços de compartilhamento é coadjuvante do processo. Uma pessoa, em uma única participação, dependendo da intensidade de sua expressão, pode carregar em sua conversa elementos comportamentais expressivos de um fã organizacional. Dessa maneira, construímos nossa proposta a partir dessa intensidade ${ }^{5}$ e não da assiduidade. Tomando como parâmetro 0 caso do Canal Viva, elencamos dez comportamentos que podem caracterizar os fãs organizacionais.

01) Trocas simbólicas em relação à organização - Fãs se reúnem em torno de um bem simbólico a fim de resgatá-lo, discuti-lo e recriá-lo. Em nosso caso específico, a novela Dancin'Days ${ }^{6}$ assume esse papel de simbolismo, gerando elementos de identificação - ou de não-identificação - entre os públicos e entre estes e a organização. A constatação desses espaços como elementos de troca simbólica é vista em diversas ocasiões, como nas categorias em que a audiência da novela retrata em suas conversas elementos pessoais (as impressões, críticas, sugestões), quando recria a narrativa, quando relembra personagens e ações, quando referencia as músicas, a moda, os comportamentos da época da trama, quando enfatiza

4 Foram coletadas na primeira etapa 1.295 expressões encontradas no Facebook, no conteúdo principal da página da novela no portal do Canal Viva e no conteúdo paralelo encontrado nos blogs lincados ao portal do Canal Viva. Na segunda etapa, foram analisadas 55 expressões do Facebook, 58 do conteúdo oficial na página da novela no portal da emissora e 28 expressões do conteúdo paralelo lincado ao portal.

6 A novela de autoria de Gilberto Braga foi ao ar no Canal Viva durante os meses de abril a outubro de 2013, no horário da meia-noite e com reprise ao meio-dia. 
outros produtos da organização, criando comparações, juízos de valores, enfim, em várias das abordagens constatadas nas narrativas presentes nos comentários.

02) Críticas ao mercado e à organização - Conversações específicas de crítica ao horário de exibição da novela, ou as escolhas da emissora em relação à programação escolhida para compor a grade do Canal Viva. Com expressões e argumentos, que ora pendiam para elementos pessoais, como para supostos conhecimentos sobre o mercado do entretenimento e dinâmicas de audiência, o fã organizacional trabalha o elemento político de seu poder.

03) Fãs como stakeholders - Os fãs em suas críticas, influenciam e são influenciados pelos objetivos da organização, compreendendo um grupo de stakeholders com poder, legitimidade e também urgência (Mitchell; Agle; Wood, 1997).

04) Socialização - Um elemento de destaque é a socialização. A predisposição a estabelecer trocas dialógicas, seja com pares, seja com a organização, mostrou-se como mais representativa desse público. Por mais que existam categorias específicas sobre a socialização do público entre si e sobre a socialização com a emissora, percebe-se, em vários comentários postados pelos mesmos, a tentativa de estabelecer conversas. Dessas interações dialógicas destacam-se tentativas de convencimentos e engajamento em torno de algo que poderia ser de interesse do público de uma forma mais generalista. Exemplo disso é quando uma telespectadora pede, em seu comentário, que os demais a ajudem a fazer uma campanha contra determinada escolha da organização em relação à exibição de um programa. 0 retorno dos fãs mostrando que se concorda com a campanha proposta exalta essa unidade em torno de um interesse e consciente do poder de reivindicação junto à organização.

05) Recirculação de conteúdo da organização - A recirculação de conteúdo a partir da produção de sentido em relação à narrativa da novela (o produto midiático) aparece fortemente. 0 público tenta construir lógicas para as ações dos personagens, assim como cria juízos a respeito da trama e prevê os próximos acontecimentos da história. Os personagens principais foram constantemente analisados e se atribui sentido a suas ações. Tais construções do público mostram a elaboração de uma dinâmica paralela, em que se discutem e recriam aspectos relativos ao produto da organização.

06) Endereçamento de conteúdos organizacionais em outras plataformas - Muitos dos comentários trazem, em suas construções, referências ao capítulo que está sendo exibido na televisão. Isso reforça a ideia de que, mesmo que 0 produto seja consumido por meio de outras plataformas, é no ambiente digital que ele é discutido, julgado, compartilhado. Existe essa condição de circulação de informações de outras mídias, uma vez que o que está na televisão se discute nas plataformas digitais on-line. Ou ainda, quando se redirecionam os fãs para outros ambientes que são fontes de informação. Por exemplo, um telespectador comenta a impossibilidade de assistir a um capitulo já exibido e vários outros apresentam hiperlinks para espaços fora do ambiente da organização, onde se pode acompanhar a trama.

07) Colecionismo e consumo de produtos físicos - Esse consumo é expresso por meio de pedidos direcionados à emissora, para que outros programas sejam exibidos, ou, ainda, para que se indiquem outros produtos referentes à trama, como o CD da trilha sonora da novela ou a versão da mesma em DVD.

08) Narradores da memória da organização - 0 fã organizacional apresenta uma predisposição a narrar a organização por meio da própria bagagem de conhecimentos. No movimento de conteúdos paralelos analisados, essa prática emerge nos comentários, apresentando a história da televisão e da própria Rede Globo. 0 pano de fundo era a escalação do elenco da novela Dancin' Days, contudo as narrativas abordaram vários outros acontecimentos, como a briga entre diretores e atores, a falência de emissoras concorrentes e alguns boatos da época sobre a forma como eram conduzidas as produções 
na emissora. Todos esses comentários eram movidos por pesquisas feitas em espaços fora do ambiente organizacional e lembranças dos mesmos sobre os fatos. São as falas não autorizadas (Baldissera, 2008), que dão novo sentido à organização e que se expandem nesses espaços de conversação do público em ambientes digitais organizacionais. Essa releitura da organização é um direito do público oficializado por esses espaços e que tem na própria rede, assim como no conhecimento adquirido pelo público, as fontes para essas criações (Mascarenhas; Tavares, 2010).

09) Tentativa de diálogo com a organização - As expressões demonstram que existe uma busca do telespectador em conversar com a organização. Em muitos casos o Canal Viva é invocado como um par para que responda às solicitações, às provocações e às duvidas dos participantes. Em outros momentos, principalmente no conteúdo paralelo, em que os direcionamentos levaram aos blogsou ao jogo de perguntas e respostas, essa tentativa de interação entre público e organização se estabeleceu, em primeiro lugar pela existência de um personagem real - o autor do blog-e pela intimidade expressa na conversa e, no segundo caso, pelas respostas diretas ao que estava sendo proposto na postagem realizada pela emissora.

10) Construção de um referencial mítico sobre os produtos - Vários personagens da trama são citados constantemente como elemento de identificação do público com a organização. Ao discutir esses personagens e seus comportamentos, 0 público integra-se ao produto da emissora, relembrando histórias pessoais - como as telespectadoras que confessaram usar meias de lurex como a personagem de Sônia Braga, ou aqueles que lembravam a trilha sonora da trama ou a febre da discoteca - e aspectos sociais - como a ditadura, o comportamento da sociedade da época, entre outros. A memória dos telespectadores serviu, em muitos desses elementos referenciais míticos, como ponto constitutivo das expressões publicadas, que foram analisadas a partir do elemento mnêmico como sendo central no comportamento do fã organizacional.

\section{O CANAL VIVA E O RELACIONAMENTO COM OS FÃS ORGANIZACIONAIS NAS PLATAFORMAS DIGITAIS}

Existe no Grupo Globo uma ideia de transparência organizacional por meio da expressão de sua ideologia e seu posicionamento de identidade, chamado pela organização de essência. Há um reforço desse posicionamento da organização quando, por meio das plataformas digitais, o público tem acesso àquilo que compôs a memória da organização; porém de forma tácita, ou seja, contada a partir dos registros da própria Globo (Matos; Lopes, 2008). A impossibilidade de interação do público com as informações contidas nesses dois ambientes - 0 da essência organizacional e o da memória - retrata uma realidade bastante comum nas organizações, de uma forma geral: a indisposição para a interação com o público.

A organização entende os espaços de compartilhamento de conhecimentos - as plataformas de redes sociais on-line-como importantes para o processo de comunicação com os públicos. Ao disponibilizar espaços institucionalizados, os pontos de identificação com os fãs tornam-se mais evidentes, pois a oportunidade de diálogo e compartilhamento de conteúdo se estabelece de forma mais rápida. Ao estar em praticamente todos os sites de redes sociais e ao explorar essa presença indicando caminhos oficiais para o público estar nesses canais, a emissora se faz presente nos ambientes e se aproxima de um comportamento dos fãs.

Porém, estar presente não significa, necessariamente, ter uma estratégia definida de atuação nesses espaços. Seguindo a dinâmica construída para a análise dos comentários, nossos resultados indicam três movimentos. No primeiro movimento, as postagens, em sua maioria, direcionam o público para o portal, trazendo personagens, histórias e contextos que chamam 
atenção do público. No segundo movimento, as postagens são mais carregadas de informações e com a incidência de hipermídias - trechos dos capítulos e entrevistas em vídeo, imagens de cenas - para ajudar a compor o conteúdo publicado. No terceiro movimento, de conteúdos paralelos, os telespectadores encontram postagens que extrapolam os limites da telenovela e amplificam os discursos com curiosidades, contextos, enfim, outros elementos que compõem a atmosfera da emissora. Nos três movimentos, o público, indiferente ao que estava sendo publicado, considerou a emissora como um par, um ator do processo de socialização e compartilhamento de conhecimento. Mesmo assim, a emissora não se manifestou em nenhum dos espaços de comentários dessas postagens.

Se, por um lado, essa postura de silêncio pode significar um entendimento sobre o que seria um fandom, deixando que a expressão do público seja majoritária e livre de interferências organizacionais - no sentido mais libertário do espaço de compartilhamento (Jenkins, 2009) -, por outro lado, a ausência de um retorno da emissora sobre tantas manifestações pode significar uma falta de atenção aos anseios do público. Um posicionamento que poderia dar conta disso, por exemplo, seria o uso de personagens propício ao negócio da organização, como intermediários no processo de diálogo dela com seus fãs. Essa postura reforçaria a ideia de ícone cultural e ajudaria na referência mítica, própria dos fãs. Ao mesmo tempo, consolidaria a necessidade do diálogo, da interação e da criatividade comunicativa, exigências do meio digital com as organizações (Terra, 2011).

\section{CONSIDERAÇÕES FINAIS}

O Canal Viva, ao disponibilizar para sua audiência uma programação majoritariamente vinculada ao passado, contribui para que se crie no imaginário do telespectador uma exultação hedônica das experiências vividas ou sabidas, dos locais, do tempo, dos hábitos e costumes.

0 prazer com as coisas do passado, relacionado a uma frustração com o presente, amplia um cenário de identificação do público com suas nostalgias e saudosismo - preceitos relevantes para uma economia afetiva que, em virtude desses aspectos, reconfigura a fidelidade, o pertencimento e, por assim dizer, a identificação do público consumidor (fã) com a marca (Canal Viva). Nos espaços de compartilhamento de conhecimentos, ou como nós chamamos anteriormente, nos fandoms organizacionais, a possibilidade de recriar o que foi vivido é pulsante e pode, por meio de uma postura comunicacional por parte da organização, ser elemento relacional entre ela e seus públicos.

Esse incentivo é para que o fã participe dos espaços disponibilizados, criando conteúdos a partir de suas lembranças, individuais, coletivas ou organizacionais. É a partir da polissemia dessas narrativas que a comunicação se torna participativa e integradora dos anseios do público. Assim, uma hipótese que pode ser levantada é: no caso da adoção de uma estratégia de comunicação organizacional dialógica, o Canal Viva ampliaria, por meio desses estímulos aos discursos do público, o comportamento típico da cultura dos fãs, ou seja, a possibilidade de, em espaços próprios, e com presença de pares, recriar histórias de interesses do grupo? Esse ideal de tornar o público produtor dos discursos organizacionais pode vir a ser uma política de comunicação para as organizações, percebendo os fãs organizacionais como uma dimensão de público com o qual se relacionar em suas especificidades.

Assim como para o Canal Viva ${ }^{7}$ a memória é um ponto de identificação com o fã organizacional -e as trocas podem ocorrer, uma vez que as incidências encontradas sejam transformadas em experiências e posturas comunicacionais a serem adotadas pela

7 Evidentemente compreendemos que existem especificidades que podem favorecer o Canal Viva devido ao caráter mítico e nostálgico de seus produtos, programas televisivos antigos 
organização, outros segmentos podem encontrar quais os elementos das expressões que criam essa proximidade com o público ao explorar os espaços disponibilizados para o compartilhamento de conhecimento. A partir disso, quaisquer organizações podem estabelecer condutas de relacionamento com seus fãs em processos de identificação e narração da memória. Para tanto, novos estudos e pesquisas precisam levar em consideração os comportamentos e perfis dos diferentes tipos de fãs.

\section{REFERÊNCIAS}

AAKER, David; JOACHIMSTHALER, Erich. Como construir marcas líderes. Porto Alegre: Bookman, 2007.

BALDISSERA, Rudimar. Comunicação organizacional: uma reflexão possível a partir do paradigma da complexidade. In: OLIVEIRA, Ivone; SOARES, Ana T. (Org.). Interfaces e tendências da comunicação no contexto das organizações. São Caetano do Sul, SP: Difusão, 2008. p. 149-177.

BARBOSA, Lívia; CAMPBELL, Colin. Cultura, consumo e identidade. Rio de Janeiro: FGV, 2006.

BENEDUZZI, Luis F. Memória, restos e nostalgia: um olhar sobre a imigração italiana no Rio Grande do Sul. Métis: História \& Cultura, Caxias do Sul, RS, v. 4, n. 8, p. 215-231, 2011.

CIRIBELI, João Paulo; PAIVA, Victor Hugo Pereira. Redes e mídias sociais na internet: realidades e perspectivas de um mundo conectado. Revista Mediação, Belo Horizonte, v. 13, jan./jun. 2011.

COPPA, Francesca. A brief history of media fandom. In: HELLEKSON, Karen; BUSSE, Kristina (Ed.). Fan fiction and fan communities in the age of the internet. Jefferson, NC: McFarland \& Company, Inc. Publishers, 2006. p. 41-59.

GOULDING, Christina. Romancing the past: heritage visiting and the nostalgic consumer. Psychology \& Marketing, Malden, v. 18, n. 6, p. 565-592, 2001.

HOLBROOK, Morris B. Nostalgia and consumption preferences: some emerging patterns of consumer tastes. Journal of Consumer Research, Chicago, v. 20, n. 2, p. 245-256, 1993.

HOLBROOK, Morris B; SCHINDLER, Robert M. Nostalgic bonding: exploring the role of nostalgia in the consumption experience. Journal of Consumer Behaviour, v. 3, n. 2, p. 107-127, 2003.

IZQUIERDO, Iván. A arte de esquecer. Rio de Janeiro: Vieira \& Lent, 2004.

JENKINS, Henry. Cultura da convergência. 2. ed. São Paulo: Aleph, 2009.

MAIA, Aline. Telenovela, projeção e identidade e identificação na modernidade líquida. Revista E-Compós, Brasília, ago. 2007. Disponível em: <http://www.compos.org.br/ seer/index.php/e-compos/article/viewFile/174/175>. Acesso em: 27 maio 2012.

MASCARENHAS, Alan; TAVARES, Olga. A inteligência coletiva do fandom na rede. In: CONGRESSO DE CIÊNCIAS DA COMUNICAÇÃO DA REGIÃO NORDESTE, XII, Campina Grande, PB, 2010. Anais... São Paulo: Intercom, 2010. Disponível em: <http://www.intercom.org.br/papers/regionais/nordeste2010/resumos/R23-1409-1.pdf>. Acesso em: 13 mar. 2013. 
MATOS, Florinda; LOPES, Albino. Gestão do capital intelectual: a nova vantagem competitiva das organizações. Comportamento Organizacional e Gestão, Lisboa, v. 14, n. 2, p. 233-245, 2008.

MITCHELL, Ronald; AGLE, Bradley; WOOD, Donna J. Toward a theory of stakeholder identification and salience: defining the principle of who and what really counts. Academy of Management Review, New York, v. 22, n. 4, p. 835-886, oct. 1997.

NASSAR, Paulo. Relações públicas na construção da responsabilidade histórica e no resgate da memória institucional nas organizações. 2. ed. São Caetano do Sul, SP: Difusão, 2008.

NATAL, Georgia. Lovemarks: a relação fã-consumidor e as marcas do coração na internet. In: Anais do // Gamepad-Seminário de Games, Comunicação e Tecnologia. Novo Hamburgo: Feevale, 2009. p. 47-51. Disponível em: <https://aplicweb.feevale.br/ site/files/documentos/pdf/28269.pdf>. Acesso em: 26 maio 2012.

PARADA, Augusto. Fãs organizacionais e a memória no relacionamento com as organizações: um estudo do Canal Viva. Tese (Doutorado em Ciências da Comunicação) - Universidade do Vale do Rio dos Sinos, 2015.

POLLAK, Michael. Memória e identidade social: estudos históricos. Revista Estudos Históricos, Rio de Janeiro, CPDOC/FGV, v. 5, n. 10, p. 200-212, 1992.

ROBERTS, Kevin. Lovemarks: o futuro além das marcas. São Paulo: Makron Books, 2005.

SANDVOSS, Cornel. Fans: the mirror of consumption. Cambridge: Polity, 2005.

TERRA, Carolina. 0 que as organizações precisam fazer para serem bem vistas nas mídias sociais sob a ótica da comunicação organizacional e das relações públicas. In: Anais do V Abrapcorp, 2011. Disponível em: <http://www.abrapcorp.org.br/ anais2011/ trabalhos/trabalho_carolina.pdf>. Acesso em: 03 abr. 2012.

Artigo recebido em 02.03.2015 e aprovado em 28.04.2015. 